\title{
NONLINEAR EXCITATION OF CONVECTIVE CELLS BY MODE COUPLING OF DRIFT WAVES
}

H. OKUDA AND C, Z, CHENG

\section{PLASMA PHYSICS LABORATORY}

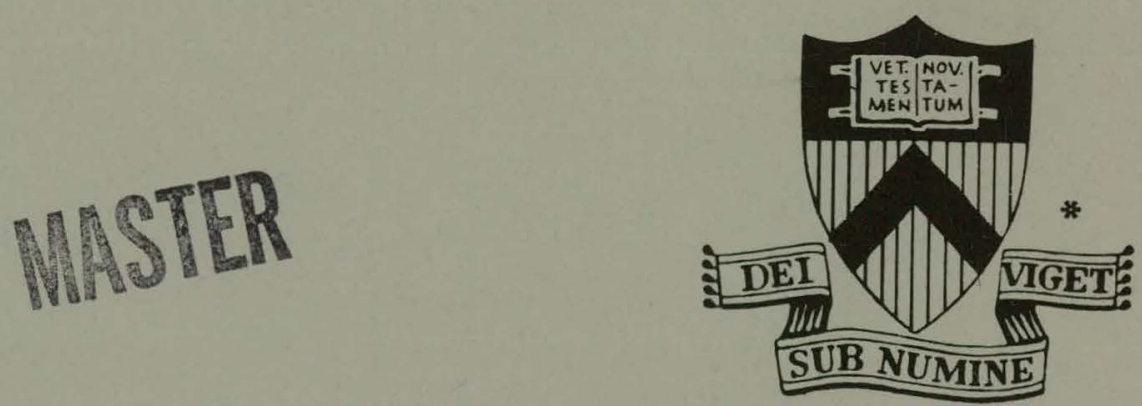

\section{PRINCETON \\ UNIVERSITY PRINCETON, NEW JERSEY}

This work was supported by U.S. Energy Research and Development Administration Contract EY-76-C-02-3073. Reproduction, Translation, publication, use and disposal, in whole or in part, by or for the United States Government is permitted. 


\section{DISCLAIMER}

This report was prepared as an account of work sponsored by an agency of the United States Government. Neither the United States Government nor any agency Thereof, nor any of their employees, makes any warranty, express or implied, or assumes any legal liability or responsibility for the accuracy, completeness, or usefulness of any information, apparatus, product, or process disclosed, or represents that its use would not infringe privately owned rights. Reference herein to any specific commercial product, process, or service by trade name, trademark, manufacturer, or otherwise does not necessarily constitute or imply its endorsement, recommendation, or favoring by the United States Government or any agency thereof. The views and opinions of authors expressed herein do not necessarily state or reflect those of the United States Government or any agency thereof. 


\section{DISCLAIMER}

Portions of this document may be illegible in electronic image products. Images are produced from the best available original document. 


\section{NOTICE}

This report was prepared as an account of work sponsored by the United States Government. Neither the United States nor the United States Energy Research and Development Administration, nor any of their employees, nor any of their contractors, subcontractors, or their employees, makes any warranty, express

or implied, or assumes any legal liability or responsibility for the accuracy, completeness or usefulness of any information, apparatus, product or process disclosed, or represents that its use would not infringe privately owned rights.

Printed in the United States of America.

Available from

National Technical Information Service

U. S. Department of Commerce 5285 Port Royal Road Springfield, Virginia 22151

Price: Printed Copy \$_ $\$$; Microfiche $\$ 3.00$

$$
\begin{gathered}
\text { *Pages } \\
1-50 \\
51-150 \\
151-325 \\
326-500 \\
501-1000
\end{gathered}
$$$$
\text { NTIS }
$$

Selling Price

$\$ 4.00$

5.45

7.60

10.60

13.60 


\title{
Nonlinear Excitation of Convective Cells \\ by Mode Coupling of Drift Waves
}

\author{
H. Okuda and C. Z, Cheng \\ Plasma Physics Laboratory, Princeton University, \\ Princeton, New Jersey 08540
}


Nonlinear Excitation of Convective Cells by Mode Coupling of Drift Waves*

\author{
H. Okuda and C. Z. Cheng \\ Plasma Physics Laboratory, Princeton University, \\ Princeton, New Jersey 08540
}

ABSTRACT

It is shown that the nonlinear interaction of drift waves resonantly excites the convective cells at the wavelengths comparable to the ion gyroradius $\left(k_{1} \rho_{i} \sim 1\right)$ where the drift waves are highly dispersive and the growth rates are the maximum. The results of numerical simulations are consistent with theoretical predictions. The effect of magnetic shear is also considered. 
Drift wave instabilities have been of current interest both in theory ${ }^{1,2}$ and toroidal confinement experiments ${ }^{3-7}$ because of their potential importance on anomalous plasma diffusion in a magnetic field. There is experimental evidence for the presence of low frequency fluctuations of the order of diamagnetic drift frequency. The observed spectrum, however, is often very broad either peaking at zero frequency with monotonic decay with the frequency ${ }^{3,4}$ or peaking at both $\omega \approx 0$ and $\omega=\omega_{e}^{*} \cdot^{5}$ It has been observed recently that the drift instabilities excite convective cells which then cause anomalous diffusion. 8

The importance of plasma diffusion due to convective cells has been confirmed in low density multipoles. 9,10 The scaling of diffusion coefficient with respect to plasma density and magnetic field has been shown to agree with the theoretical predictions. 10,11 while the nonlinear excitation of convective cells due to drift instabilities has been observed in the numerical simulation, 8 the coupling between convective cells and drift instabilities has never been considered before.

It is the purpose of this paper to present a physical interpretation showing such a coupling is, indeed, possible and is quite important for plasma confinement. In particular, resonant interaction can take place at wavelength of the order of the ion gyroradius where the drift type instabilities have the maximum growth rate.

Let us.consider a slab plasma in a strong magnetic field in $z$ direction. The plasma is nonuniform in $x$. When there is no 
shear, convective cells are purely damped modes given by, for $\omega_{\mathrm{pi}}>\Omega_{\mathrm{i}}, 11$

$$
\omega=-i k_{\perp}^{2} D_{\perp} \quad\left(k_{\| 1}=0\right),
$$

where $D_{\perp}$ is the turbulent ion viscosity. In a uniform thermal plasma, it is well known that this mode leads to anomalous plasma diffusion. ${ }^{11}$. In an inhomogeneous plasma, convective cells, Eq. (1), persist; however, their amplitudes are smaller because of the presence of ion flute modes

$$
\omega=\omega_{i}^{*}
$$

which extracts fluctuation energy from the convective cells due to their higher frequency. $12 \omega_{i}^{*}$ is the ion diamagnetic drift frequency. The convective cells may be weakly unstable due to plasma dissipation in a nonuniform plasma ${ }^{12}$ and are localized near the rational surfaces. Their growth rates are, in general, small in a high temperature plasma. When there are large amplitude convective cells present, then the convective diffusion is important. Large convective cells may be generated in the process of plasma creation, ${ }^{10}$ and also, drift type instabilities can feed energy to convective cells which then cause large plasma diffusion. 8

Consider, for example, the collisionless drift instability (universal mode) in a low density plasma slab. The dispersion 
relation is given by ${ }^{13}$

$$
\frac{\omega-\omega_{e}^{*}}{k_{\|:} v_{e}} z\left(\frac{\omega}{k_{\|} v_{e}}\right)+\frac{T_{i}}{T_{e}} \frac{\omega-\omega_{i}^{*}}{k_{\|{ }^{v}}^{v_{i}}} z\left(\frac{\omega}{k_{\| v^{v}}}\right) \Gamma+1+\frac{T_{i}}{T_{e}}=0
$$

where $\Gamma=\exp \left(-k_{\perp}^{2} \rho_{i}^{2}\right) I_{0}\left(k_{\perp}^{2} \rho_{i}^{2}\right)$. For $v_{i} \ll \omega / k_{\|} \leqslant v_{e}$, Eq.

gives unstable modes and the typical numerical solution of the dispersion relation is plotted in Fig. 1 for fixed $k_{\|}=2 \pi n / L_{z}$. For $k_{\perp} p_{i} \ll i$, Eq. (3) gives

$$
\omega=\omega_{e}^{*} \Gamma /(2-\Gamma)
$$

As $k_{1} \rho_{i}$ approaches 1 , both the growth rate and the frequency reach the maximum and then decrease for $k_{\perp} \rho_{i} \geq 1$.

Remembering that the drift modes shown in Fig. 1 have the same $k_{11}$, we note the two drift modes 1 and 2 , for example, with the same frequency $\omega$ can resonantly excite convective cells $\left(\omega=0, k_{\| 1}=0\right)$ with the resultant $\underset{\sim}{k_{\perp}}=\underset{\sim}{k_{1}}+\underset{\sim}{k_{12}}$. Since the linear damping rate of the convective cells is very small, it is clear that nonlinear excitation becomes important even for small amplitude drift waves.

Consider the presence of small amplitude drift waves described by the linear theory. To describe the nonlinear excitation of convective modes, let us use the continuity equation for the ions. 


$$
\frac{\partial n_{i}}{\partial t}+\nabla \cdot\left(n_{i \sim} v\right)=0
$$

Since we are looking at the beating of the two drift waves to generate the convective cells $\left(k_{\|}=0, \omega=0\right)$, only the perpendicular flux of $\mathrm{n}_{\sim}$ contributes. Then the nonlinear fluxes are given by $\nabla_{\perp} \cdot\left(\mathrm{n}_{\mathrm{O} \sim 2} \mathrm{v}_{2}\right)$ due to the convective derivative of ${ }_{\sim \mathrm{E}} \mathrm{v}=$

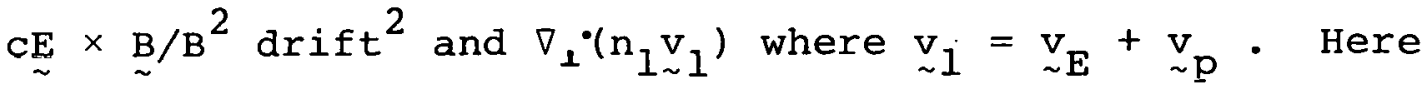
$\underset{\sim}{v_{2}}=c\left(\underset{\sim}{v} \underset{\sim}{\nabla} \underset{\sim}{\mathrm{E}_{\perp}} / \Omega_{i} B\right.$ and $\underset{\sim p}{v}=\left(c / B \Omega_{i}\right)\left(\underset{\sim}{\mathrm{E}_{\perp}} / \partial t\right)$. Writing

$$
\begin{aligned}
& \mathrm{n}_{1}(\underset{\sim}{x}, t)=\sum_{\underline{v}}\left(n_{k}^{\mathrm{d}} \exp (i \omega t+\underset{\sim}{i \underset{\sim}{x}})+c \cdot c \cdot\right) \\
& \phi(\underset{\sim}{x}, t)=\sum_{\underset{\sim}{k}}\left(\phi_{k}^{\mathrm{d}} \exp (i \omega t+\underset{\sim}{i \underset{\sim}{x} \cdot \underset{\sim}{x})}+c \cdot c \cdot),\right.
\end{aligned}
$$

for the drift waves and similar expression for the convective cells, we find, for $k_{x}>k \equiv d \ell n n_{0} / d x$, from (4)

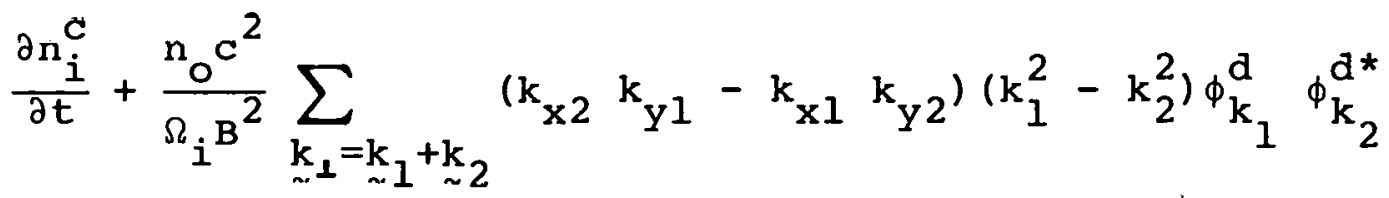

$$
\begin{aligned}
& +\frac{c}{B} \sum_{k_{1}=k_{1}+k_{2}}\left(k_{x 1} k_{y 2}-k_{x 2} k_{y 1}\right) \phi_{k_{1}}^{d} n_{i k_{2}}^{d^{*}}=0
\end{aligned}
$$

$\nabla_{\perp} \cdot\left(\mathrm{n}_{1} \mathrm{v}_{\sim \mathrm{p}}\right)$ is smaller than $\nabla_{\perp}\left(\mathrm{n}_{0} \mathrm{v}_{2}\right)$ by $k / k$ and is neglected. 
A similar equation is obtained for the electron density using

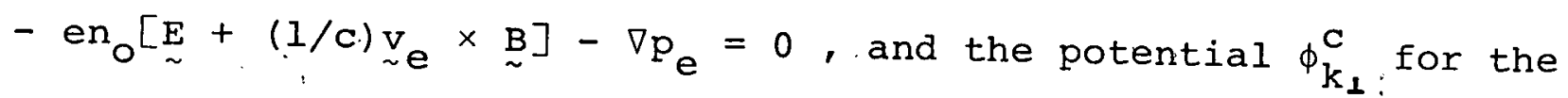
convective cells is found from the Poisson equation $\mathrm{k}_{1}^{2} \phi_{\mathrm{k}_{1}}^{\mathrm{c}}=$ $4 \pi e\left(n_{i}^{c}-n_{e}^{c}\right)$.

$\frac{\partial \phi_{k_{\perp}}^{c}}{\partial t}+\frac{\omega_{p i}^{2}}{\Omega_{i}^{2}} \frac{c}{B} \frac{1}{k_{\perp}^{c 2}} \sum_{k_{\perp}=k_{1}+k_{2}}\left(k_{x 2} k_{y l}-k_{x l} k_{y 2}\right)\left(k_{1}^{2}-k_{2}^{2}\right) \phi_{k}^{d} \phi_{k_{2}}^{d *}$

$$
\begin{aligned}
& +\frac{c}{B} \frac{1}{k_{\perp}^{c \cdot 2}} \sum_{\substack{k_{\perp}=k_{\sim}+k_{\sim} \\
\sim}} k_{2}^{2}\left(k_{x 1} k_{y^{2}}-k_{x 2} k_{y \cdot 1}\right) \phi_{k_{1}}^{d} \phi_{k_{2}}^{d *} \\
& =-k_{\perp}^{c 2} D_{\perp} \phi_{k_{\perp}}^{c},
\end{aligned}
$$

where the well-known linear viscous damping is added to the right-hand side of (6). In (6), the nonlinear term due to convective $\mathrm{CE} \times \mathrm{B} / \mathrm{B}^{2}$ drift is greater than the $\mathrm{CE} \times \mathrm{B} / \mathrm{B}^{2}$ term by $O\left(\omega_{\mathrm{pi}}^{2} / \Omega_{i}^{2}\right):{ }^{2}$. We emphasize here the coupling coefficient for the excitation of convective cells is greater than the previously found one for the drift waves ${ }^{2}$ by $\left(k_{\perp}^{2} \lambda_{D}^{2}\right)^{-1}$ and scales as $k^{2}$ instead of $\mathrm{k}^{4}$. This is because the convective cells $\left(\mathrm{k}_{11}=0\right)$ are not quasineutral and large elecțric fields are associated with them.

When the nonlinear driving term becomes greater than the linear damping term, then Eq. (6) predicts the convective cells grow as $\exp \left[\left(\gamma_{1}+\gamma_{2}\right) t\right]$ as a result of the nonlinear interaction of 
drift waves. From Fig. 1, we see that the longest convective cells $\left.\underset{\sim}{\left(k_{1}\right.}+\underset{\sim}{k_{12}} \approx 0\right)$ tend to grow the fastest. As the convective cells become large amplitudes, they not only interact back on the drift waves but also interact by themselves resulting in strong turbulence and anomalous diffusion. At that stage, full nonlinear treatment is necessary.

When a magnetic shear is introduced, drift modes are found to remain unstable in laboratory experiments and the convective rnodes may become unstable. In addition to the viscosity damping, the convective cells now damp due to the phase mixing of the electrons, $\left\langle k_{\|} v_{e}\right.$, in a collisionless plasma. I4 Fquation (11), however, predicts the convective cells are always excited regardless of the shear damping due to the resonant excitation. Then the shear is very strong, convective cells may never be excited since the drift instabilities may be stabjlized by shear and other nonlinear effects before the convective cells can be excited.

Let us now look at the results of three dimensional simulations on collisionless drift instabilities. The simulation model ${ }^{8}$ is a cylindrical plasma with the external magnetic field $\underset{\sim}{\mathrm{B}}=\mathrm{B}_{\mathrm{o}}\left[\hat{\mathrm{z}}+\mathrm{B}_{\mathrm{p}}(r) \hat{\theta}\right]$. The sheared magnetic field is introduced by $B_{p}(r)=2 \pi r / q L_{z}$ with $q-q_{0}\left(1+\lambda r^{2} / a^{2}\right)$. The initial density is $n(r)=n_{0} \operatorname{cxp}\left(-\alpha r^{2} / a^{2}\right)$.

Figure 2 shows the time development of the drift $(n=1$, $\left.\omega \approx \omega_{e}^{*}\right)$ and convective cells $(n=0, \omega=0)$ for the shearless case $\left(B_{p}=0\right)$ with $m_{i} / m_{e}=100, T_{e} / T_{i}=4, \alpha=4, \Omega_{e} / \omega_{p e}=5$, 
$L_{z}=1280 ; \mathrm{a}=32, \mathrm{v}_{\mathrm{e}}=2$ where the length and speed are normalized by the grid size $\Delta$ and $\omega_{p e} \Delta \cdot^{8}$ we see several different drift modes grow at about the expected rate from the linear theory $\left(\gamma / \Omega_{i} \cong 0.06\right)$. Convective cells also grow with time but start growing at around $\omega_{p e} t=600$, at a somewhat later time when the drift modes are small but finite amplitudes. The threshold given by Eq. (6) agrees reasonably well with the simulation. All the convective modes grow at about the same growth rate which is nearly twice of the rate of the drift modes. When the drift modes saturate at $\omega_{p e} \mathrm{p}^{t} \approx 1200$, their amplitudes decrease slowly. The convective modes also saturate at about the same time but do not damp away since they are the normal modes for a homogeneous plasma. These observations clearly support the theoretical interpretation that the convective modes are driven unstable to large amplitude by the drift modes. The amplitude of the convective cells from the initial noise level agrees with Eq. (6). It is clear that the large amplitude convective cells can cause substantially greater diffusion than that due to drift waves. 8 When a weak shear is introduced with $q_{0}=1.1, \lambda=2.5$, and $L_{s} / L_{n} \simeq 50$, there is little effect on the anomalous plasma diffusion. Figure 3 shows the time development of $\operatorname{drift}(n= \pm 1)$ and convective cells $(n=0)$. The growth rates for the drift modes $(n= \pm l)$ are slightly reduced from the shearless case. The growth of the convective modes. $(n=0)$ takes off at $\omega_{p e} t=800$ slightly later than the shearless case presumably due to smaller growth rates of drift instabilities. The damping rate of the convective cells due to shear may be estimated 


$$
<k_{\|} v_{e}>=(m / r)\left(B_{p} / B\right) v_{e} \cong 5 \times 10^{-3} \omega_{p e}^{-1},
$$

and this damping is very small compared with the nonlinear driving term due to drift instabilities. The measured frequency spectrum confirms the presence of drift $\left(\omega=\omega_{e}^{*}\right)$ and the convective modes $(\omega \approx 0)$.

When the shear becomes stronger, the growth rate of the drift modes becomes smaller and the shear damping of the convective cells becomes larger. Results of simulations for $L_{s} / L_{n}=25$ and $m_{i} / m_{e}=400$ indicate that drift modes are unstable for $n=0$ perturbation which leads to anomalous plasma diffusion about. three times smaller than the previous cases. Convectịve cells are found to be substantially smaller than the drift waves. For $\mathrm{L}_{\mathrm{s}} / \mathrm{L}_{\mathrm{n}}=10$ and $\mathrm{m}_{\mathrm{i}} / \mathrm{m}_{\mathrm{e}}=400$ case, we found that the $\mathrm{drift}$ instabilities were very weak in good agreement with the theoretical expectations for shear stabilization. No convective cells were found for this case. This is because the small diffusion due to drift instabilities lead them to marqinal stability and no driving terms were present for the convective cells. While we have looked at only the collisionless drift instability, it is clear that the convective cells can be nonlinearly generated whenever the dispersion relation has a peak for $\omega$ as shown in Fig. 1. Another such example is the trapped particle instabilities in tokamaks. 15 While the magnetic shear tends to reduce the nonlinear-driven terms for the qeneration of the convective cells, effects 
of particle collisions and mirror trapping ${ }^{16}$ have to be included for better treatment in toroidal devices since they compete with the stabilizing shear effects. Furthermore, while the simulations treated the initial value problem, laboratory experiments are in steady state in which the turbulence is continuously driven by the energy input. Under such conditions, convective cells may be driven to larger amplitudes.

The authors acknowledge several important discussions with Dr. R. I. Berger and Dr. A. Haseqawa. 
REFERENCES

*This work was supported by United States Energy Research and Development Administration Contract E(11-1)-3073.

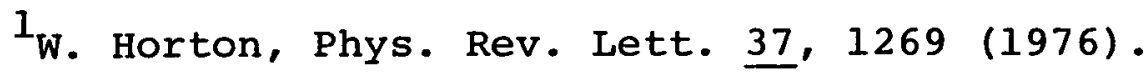

${ }^{2}$ A. Hasegawa and K. Mima, (To be published)

${ }^{3}$ E. Mazzucato, Phys. Rev. Lett. $\underline{36}, 792$ (1976).

${ }^{4}$ C. M. Surko and R. E. Slusher, Phys. Rev. Lett. 37 , 1747 (1976).

${ }^{5}$. Okabayashi and V. Arunasalum, PPPL-1310 (To be published)

${ }^{6}$ S. M. Hamberger, L. E. Sharp, J. B. Lister, and S. Mrowka, Phys. Rev. Lett. 37,1345 (1976).

7 M. W. Alcock, D. E. T. F. Ashby, J. G. Gordey, T. Edlington, W. H. W. Fletcher, E. M. James, J. Malmberg, A. C. Riviere, D. F. H. Start, and D. R. Sweetman, IAEA 6th Conference on Plasma Physics and Controlled Fusion, CN35/D12 (1976).

${ }^{8} \mathrm{C} . \mathrm{Z}$. Cheng and H. Okuda, Phys. Rev. Lett. $\underline{38}, 708$ (1977)

${ }^{9}$ T. Tamano, R. Prater, and T. Ohkawa, Phys. Rev. Lett. 30 , 431 (1973).

${ }^{10} \mathrm{~J}$. R. Drake, J. R. Greenwood, G. A. Navratil, and R. S. Post, Phys. Fluids 20, 148 (1977); G. A. Navratil, R. S. Post, and A. B. Ehrhardt, Phys. Fluids 20, 156 (1977). 
$1^{1}{ }_{\mathrm{H}}$. Okuda and J. M. Dawson, Phys. Fluids 16, 408 (1973).

12j. M. Dawson, H. Okuda, and B. Rosen, in Methods in Computational Physics, Vol. 16, Academic, 1176, p. 310.

13 B. B. Kadomtsev, Plasma Turbulence, p. 86 (Academic Press, 1965).

${ }^{14} \mathrm{M}$. N. Rosenbluth and C. S. Liu, 5th Furopean Conference on Controlled Fusion and Plasma Physics, Vol. I, p. 12 (1972); also H. Okúda and J. M. Dawson, Phys. Fluids 16, 1456 (1973). ${ }^{15}$ W. M. Manheimer, E. Ott, K. R. Chu, J. P. Boris, and J. D. Callen, Nucl. Fusion 162, 203 (1976). 16 T. Kamimura and J. M. Dawson, Phys. Rev. Lett. 36,313 $(1976)$ 


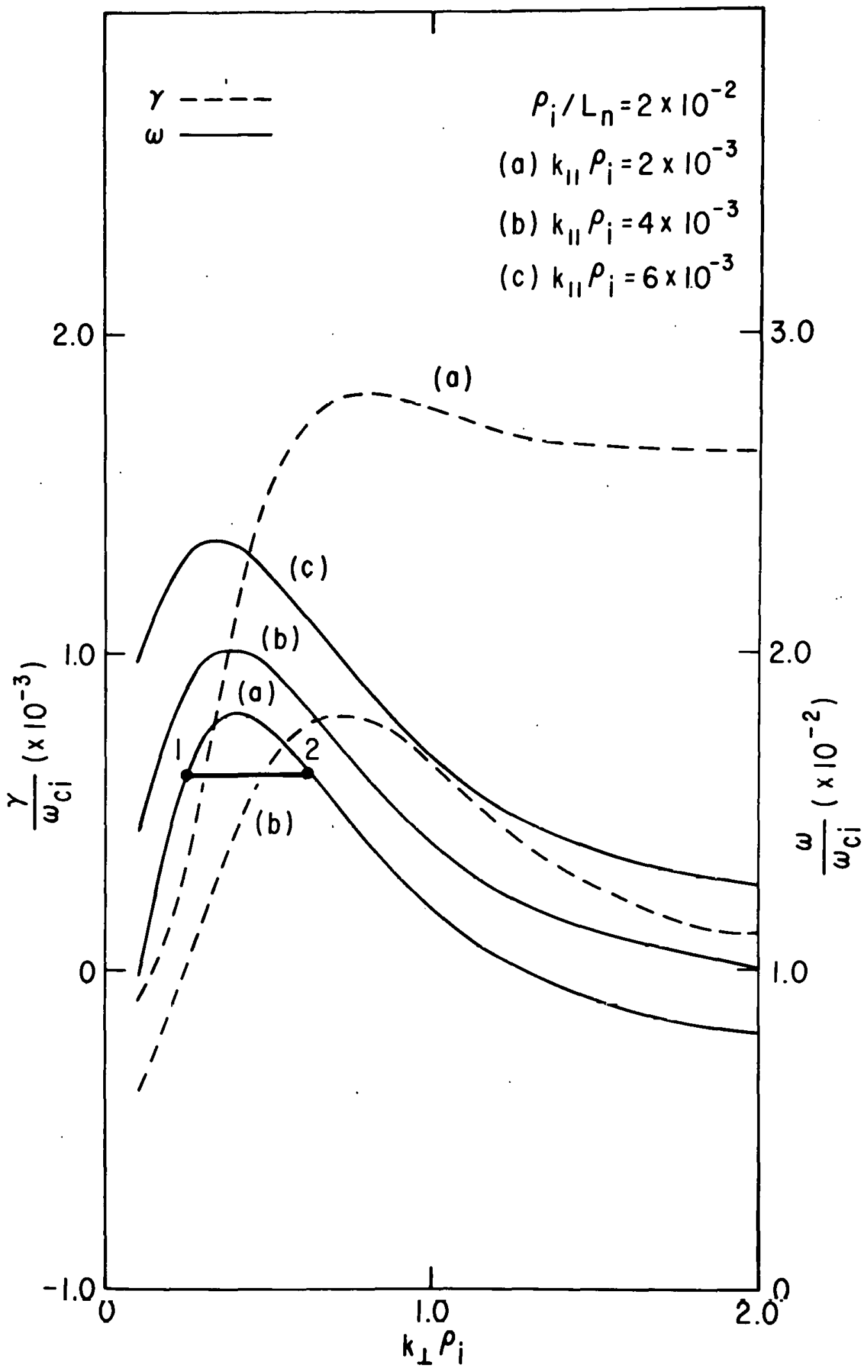

772300

Fig. 1. Numerical solution for the collisionless drift instability for a plasma of $\mathrm{m}_{\mathrm{i}} / \mathrm{m}_{\mathrm{e}}=1800$. Note the frequency and the growth rate are the maximum at

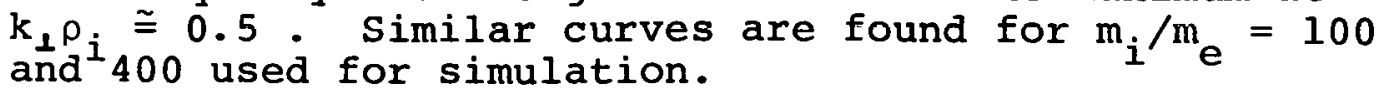



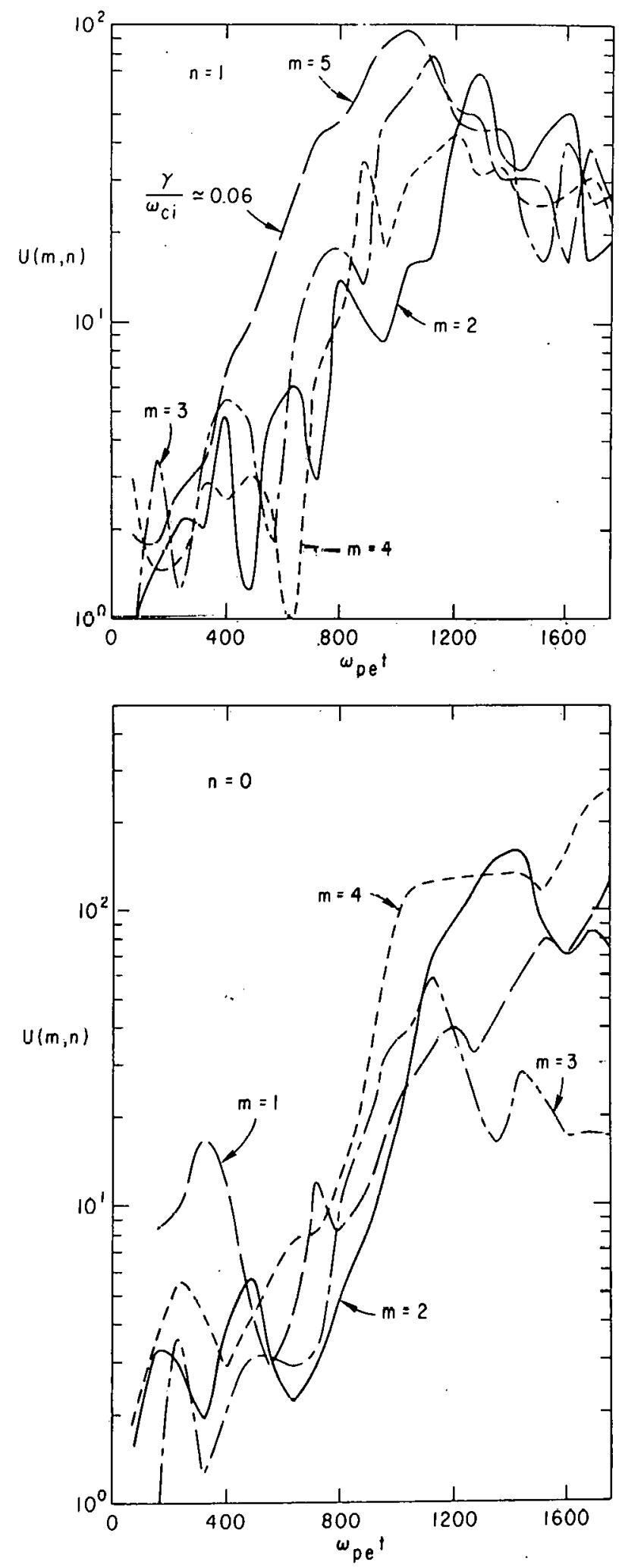

772013

Fig. 2. Time development of the electric field energy of the drift wave ( $n=1)$ and convective cells $(n=0)$ in the absence of magnetic shear. 

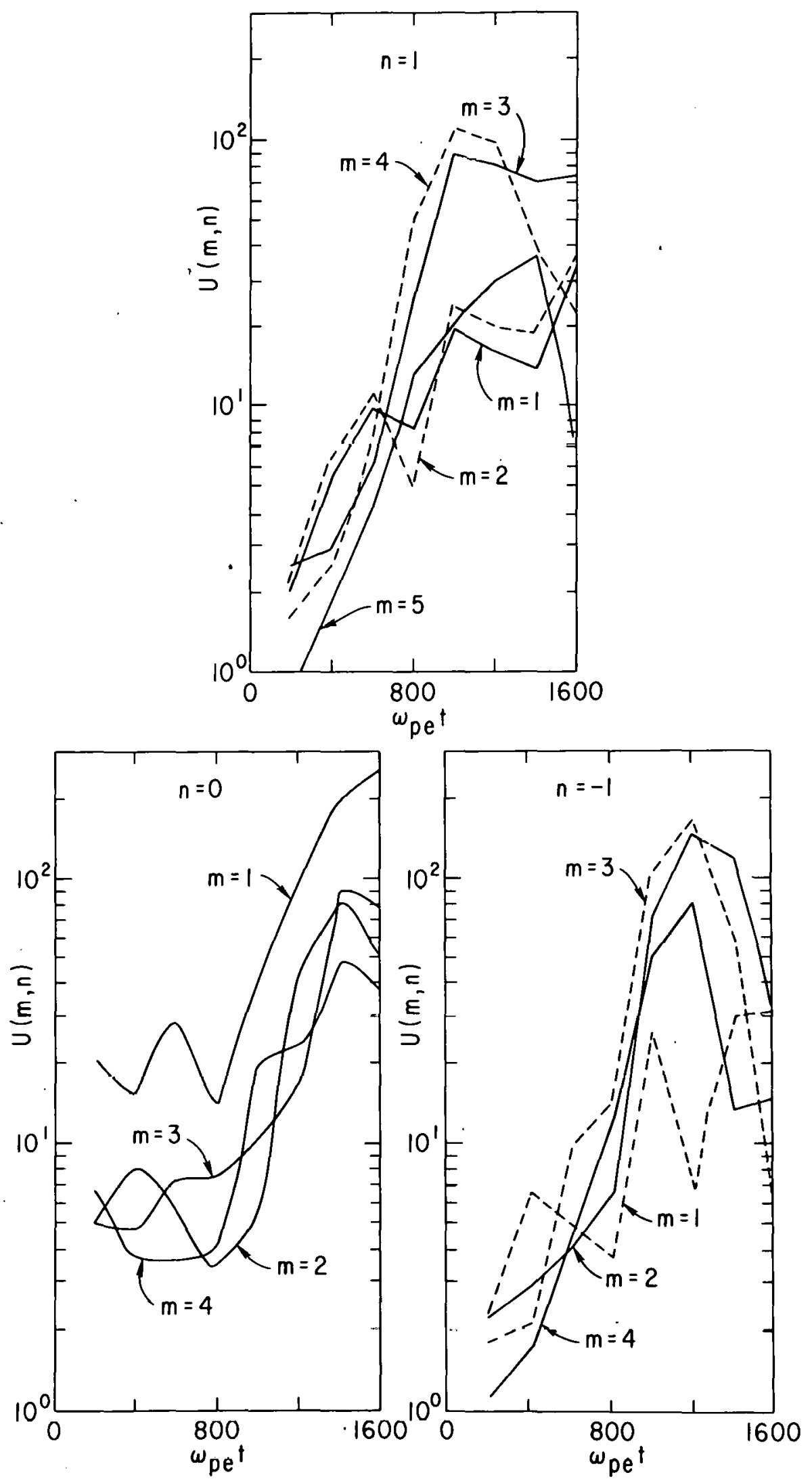

772123

Fig. 3. Time development of the electric field energy of the drift wave and convective cells in the presence of weak shear $\left(\mathrm{L}_{\mathrm{s}} / \mathrm{L}_{\mathrm{n}} \cong 50\right)$. 